Article

\title{
Pricing Policies in Managing Water Resources in Agriculture: An Application of Contract Theory to Unmetered Water
}

\author{
Francesco Galioto $^{1{ }^{1} *}$, Meri Raggi ${ }^{2}$ and Davide Viaggi ${ }^{1}$ \\ 1 Department of Agricultural Sciences, University of Bologna, Via G. Fanin, 44, 40127 Bologna, Italy; \\ E-Mail: davide.viaggi@unibo.it \\ 2 Department of Statistical Sciences, University of Bologna, Via Belle Arti, 41, 40126 Bologna, Italy; \\ E-Mail: meri.raggi@unibo.it \\ * Author to whom correspondence should be addressed; E-Mail: francesco.galioto@unibo.it; \\ Tel.: +39-51-2096-115; Fax: +39-51-2096-105.
}

Received: 15 July 2013; in revised form: 5 September 2013 / Accepted: 16 September 2013 / Published: 27 September 2013

\begin{abstract}
The paper explores how agricultural water pricing could contribute to lowering water demand when uses are unobserved (asymmetric information). The topic of the paper is justified by the fact that most water authorities worldwide do not control water uses at the farm scale. The study draws inspiration from the pricing policies of a Reclamation and Irrigation Board in Northern Italy. It analyses the optimal design of current tariff strategies with respect both to the actual regulator's goals and the cost recovery objective of an ideal regulator driven by European Water Framework Directive principles and having full information. The analysis is based on the logic of a Principal-Agent model implemented as a mathematical non-linear programming model. Given the current pricing structure and assuming zero transaction costs, the results show a relevant increase in net benefits for the ideal scenario with respect to the actual one as water use costs increase. Benefits differences between the two scenarios mark a limit in value below which mechanisms able to solve the existing asymmetries between the principal and the agents are economically desirable. The study concludes by showing that the current regulator's discriminatory strategy (pricing structure) would be better justified with higher levels of cost for water use. However, the existence of non-zero transaction costs related to the control of water uses points to the need for further research in order to analyze incentive mechanisms in the absence of water metering.
\end{abstract}


Keywords: unmetered water; asymmetric information; pricing schemes; water framework directive; irrigation; economic analysis; mathematical simulation

\section{Introduction}

The European Union, Russia and South Africa have recently reformed their water policies in order to address new water-related challenges, including population growth and climate change [1]. These water reforms have in common a transition from an approach focused on increasing water supply to one that focuses on the management of water demand. These reforms were partly devoted to identify an institutional body able to ensure a suitable management of water uses. As a result of this process, watersheds are mostly recognized to be the most effective and sustainable institutions for water governance. Another strand of action concerns the identification of policy instruments to efficiently impact the behavior of water users. In spite of the increasing attention being paid to economic instruments, this issue is not suitable for generalized solutions, since pricing schemes should take into account local and regional circumstances regarding water uses, water availability, farm size and crops grown. However, economic instruments remain explicitly promoted by the European Union (EU) through its Water Framework Directive (WFD). The WFD includes three economic concepts:

(1) Full Cost Recovery (FCR) which covers the recovery of the costs related to water services, the potential negative environmental effects of socio-economic activities and the foregone opportunities of alternative water uses (resource costs);

(2) The Polluter Pays Principle (PPP) that looks at the adequacy of contributions to compensate for the cost of environmental damage generated by users;

(3) Incentive Pricing (IP) that deals with the way in which water use is paid for and whether the right signals are transmitted to the water users.

These concepts underscore the dual purpose of charging for water use, namely financial and economic. From a financial perspective, the tariff allows the regulator to recover all or part of the capital and current costs. From an economic perspective, the tariff enables the regulator to conserve water and raise water productivity [2]. The main assumption underlying the regulator's ability to achieve one or more of the above policy objectives by way of tariffs relies on direct or indirect knowledge of the amount of water used by individual sectors or agents. Hence, water metering is a key step in allowing local authorities to develop pricing policies that adhere to EU WFD principles [3-11]. However, the most common pricing systems for irrigation water in the world [12] and in Europe [12,13] rely on area-based charges, disconnected from actual use. Indeed, water metering is extremely controversial in agriculture and greatly constrains the adoption of efficient water pricing for irrigation [2]. The result is the inability of tariffs to contribute to more efficient water use, with, in addition, the fact that higher tariffs (potentially needed in order to achieve cost recovery) hurt the less water intensive crops. This also undermines the EU WFD objective of using pricing-based incentive mechanisms to mitigate water scarcity.

From an economic point of view, the lack of water metering can be interpreted in the framework of information asymmetries between management authorities and farmers. This situation has prompted 
some researchers to study the problem of tariff design when water uses are unobserved. Unmetered water is usually priced on a per area basis $[14,15]$ but may also be priced, at least theoretically, by charging per unit fees on observable outputs or inputs $[12,16]$.

If the entire water supply cost is borne by the water users, then it makes no difference if water inputs are unobservable. A problem arises, however, when the cost of water includes public good components due to scarcity or extraction cost externalities [12]. In this case, farmers would likely decide to use more water than they would use in a situation characterized by a socially optimal allocation, and hence some kind of regulatory intervention may be desirable. Available information, such as the total harvested area, could constitute inaccurate proxies for water uses and, hence, indirect water fees may even increase inefficiencies. The pricing problem is also exacerbated when individual farmers' production technologies are unknown to the water authorities (adverse selection) [17,18] and regulation entails transaction costs associated with administration, monitoring and enforcing activities [12].

This paper aims to verify whether existing area-based tariff strategies are efficient economic instruments for water policy and to what extent alternative design in the direction of irrigated area-based instruments can help in better complying with European water policy principles.

The case study focuses on a Reclamation and Irrigation Board (RIB). This type of institution, the main provider of irrigation water in Italy, is a user-based allocation mechanism similar to others in place in some Southern EU Member States [13], and is recognized as being an appropriate institution to allow for the analysis of different kinds of tariff policies $[19,20]$. This institution provides water for users in keeping with the relevant Italian legislation and imposes a payment based on a portion of the RIB's costs, shared among users on the basis of an estimation of their expected benefits [21]. RIB pricing policies are not necessarily focused on promoting sustainable water uses. Pricing strategies are limited to the recovery of current financial costs and do not account for other financial costs, opportunity costs or costs associated with environmental externalities.

In the case of a revision of the RIB's contribution system in accordance with the FCR principles defined in the WFD, a significant restructuring of RIB water pricing systems could occur. As specified above, tariff strategies should be tailored to the specific types of distribution systems. The inability to meter water consumption requires various tools of price discrimination aimed at improving the control of water uses [22]. Specifically, the RIB in the case study offers farmers the possibility to choose between a tariff based on the total farm area and a tariff based on the irrigated area. These optional contracts generate information for the RIB about the actual production technology (which allows for a more efficient incentive system), based on the contract chosen by each farm, as well as transaction costs due to the need to monitor irrigated farmland.

Given the water demand function and the profit function of different farm types estimated in a recent research study carried out in the RIB's area [23], and assuming that farmers are profit maximizers and that the regulator seeks to meet the new requirements imposed by the Directive, we examine the contribution of improved contract design through a contract theory approach starting from the current RIB pricing strategies. The results show that benefit differences, arising from the ability to manage farmers' tariff choices, vary with increasing water use costs. Within a certain range of water scarcity, surplus differences may justify the transaction cost required to solve information asymmetries. 
The paper is divided into four sections. Section 2 describes the current pricing policies in the Case Study area. Section 3 sets out the methodology; formalizing the producer's behavior; the section identifies two different potential scenarios for the regulator's pricing strategies. Section 4 presents a numerical analysis of the identified pricing strategies based on available information about irrigation in the area, under different scenarios of cost recovery obligations and information asymmetry. Section 5 provides a discussion on how contract theory could help to define strategies able to integrate the WFD principles in actual pricing policies based on the experience carried out in this study, followed by some concluding remarks.

\section{The Case Study}

The RIB is an association of persons who own property (land and buildings) in its jurisdiction. Landowners who are associates of the RIB are required, according to the subsidiarity principle, to contribute directly to the pursuit of the general interest.

The RIB undertakes institutional (collection of contributions), operational (management) and proactive (planning) functions. With regard to the institutional functions, contributions for reclamation are enforced on all agricultural and non-agricultural assets in its jurisdiction. RIBs are also major providers of irrigation water. Pricing strategies arising from the use of irrigation water are currently designed autonomously by the RIB and vary with respect to the type of distribution system. In any case, by statute, cost allocations among associates are performed on the basis of the degree of benefit. In fact, this principle is not always rigorously met, especially when irrigation water is unmetered.

Italian RIBs have historically dealt with the recovery of operating costs. They rely on State funding for the coverage of infrastructural investments and hence are not in charge of recovering the related (capital) costs.

According to the FCR principle, with the implementation of the WFD, State intervention should drive the local population towards the self-management of water resources. Accordingly, Basin Districts [24] should lead the various economic sectors using water, including those served by the RIBs, to take responsibility of the full costs required to ensure a good hydrological status of the area under their jurisdiction. Lack of metering conditions hinders the application of cost sharing between farmers on the basis of water use. In this respect, options allowing some price discrimination are expected to favor a greater ability to control resources, ensuring a better allocative efficiency and a more rational use of water for irrigation.

The case study focuses on the RIB of Western Romagna (Consorzio di Bonifica della Romagna Occidentale - CBRO). The consortium covers an area of 195,000 ha of which 70,000 ha are plains. Fruit and wine grapes are the main crops grown in the area. Therefore, irrigation is both frequent and abundant. The study area is particularly attractive for the investigation of different water management instruments: Part of it is served by pressure pipes and part receives water via open canals. As a result, different pricing systems are also in place, including volumetric pricing in areas served by pressure pipes and area-based tariffs in the remaining parts of the RIB.

For some of the areas served by surface water, the RIB uses a pricing regime that provides the choice between two tariff options. 
The first option is a per area based tariff imposed on the entire farmland area, i.e., it does not account directly for the distinction between irrigated and non-irrigated land in individual farms. However, it takes into account the general greater share of irrigated area for smaller farms, by setting a per hectare tariff, $T^{a}\left(x_{i}\right)$, that decreases with the increase in farm size, $x_{i}$ up to a certain threshold of land size, $x^{s}$, after which it stabilizes to a flat rate per hectare. For farmers exceeding $x^{s}$, the tariff per hectare is traceable to the following formula: Here, $K$ is the tariff corresponding to the total paid for amount of land equal to $x^{s}$ and equals the integral of $T^{a}\left(x_{i}\right)$ from 0 hectares to $x^{s} ; t^{a}$ is the tariff per hectare over the remaining harvested area. Thus, if $x_{i}$ equals $x^{s}$ the average per hectare tariff would be equal to $K / x^{s}$. For larger farms, $t^{a} \times\left(x_{i-} x^{s}\right)$ will play a greater role in influencing the entire value paid by the farm, while the average (per hectare) tariff will tend to the marginal value $\left(t^{a}\right)$ as $x_{i}$ tends to $+\infty$. We define this pricing scheme as a "no incentive tariff" since it is not capable of affecting water uses.

The second option, unlike the first one, is based on a per hectare tariff proportional to the quota of irrigated farmland, $x_{i}^{i r r}$, such that: $T^{b}\left(x_{i}^{i r r}\right)=t^{b} \times x_{i}{ }^{i r r}$. We refer to this pricing scheme as "incentive tariff" since it is able to affect water uses. Here, farmers are required to declare the size of the irrigated area. This practice, based on self-reporting by farmers, and hence requiring controls by the RIB, generates specific monitoring costs that are charged by way of the water tariffs themselves.

Figure 1 describes the evolution of the per hectare tariff under the two pricing schemes as farm size $\left(x_{i}\right)$, and, respectively, irrigated land $\left(x_{i}^{i r r}\right)$, increases.

As $x_{i}$ increases, the average fee under the first pricing option (blue line) decreases from $72 € /$ ha, for farms size under $1.5 \mathrm{ha}$, to $27 € /$ ha, for huge farms. In contrast, the second pricing option (red line) is not affected by farm size and its average value is constant ( $187 € /$ ha of irrigated farmland).

This double tariff scheme is implemented for the main purpose to ensure a more equitable allocation of costs among beneficiaries, since the share of irrigated crops tend to decrease with increasing farm size. Under such circumstances an irrigation-related tariff proportional to the total farmland area would be too unbalanced for large farms.

In addition, the RIB offers the option of choosing the incentive tariff, $T^{b}\left(x_{i}^{i \text { ir }}\right)$ only to farms that are larger than 15 ha. This limit is set since the incentive tariff requires the farmer to self-report the quota of irrigated farmland, forcing the RIB to organize controls in order to verify compliance. Costs arising by direct monitoring are charged by way of the water tariffs themselves. These costs increase with the farmer's choice of the incentive tariff scheme limiting the regulator's ability to check for uses. This explains the regulator's decision to limit the choice of this tariff scheme only to large farms (that are also less numerous).

In a recent research five different clusters of farms were identified in the RIB's region [23]. Under the current policy, only two of them have the opportunity to choose between the discussed tariff schemes. The first type represents $3 \%$ of RIB farms and is characterized by an average farm size of 33.85 ha, $37 \%$ of which is covered by orchards; the second, represents $1 \%$ of RIB farms and is characterized by an average farmland area of 75.07 ha, $16 \%$ of which is devoted to orchards. The two farm types represent $21 \%$ of the area managed by the RIB. As these farm types are the only ones that can choose between the two tariff options, they are also the only ones considered in this study. 
Figure 1. Average tariff trends with increasing total and irrigated farmland for the two tariff options.

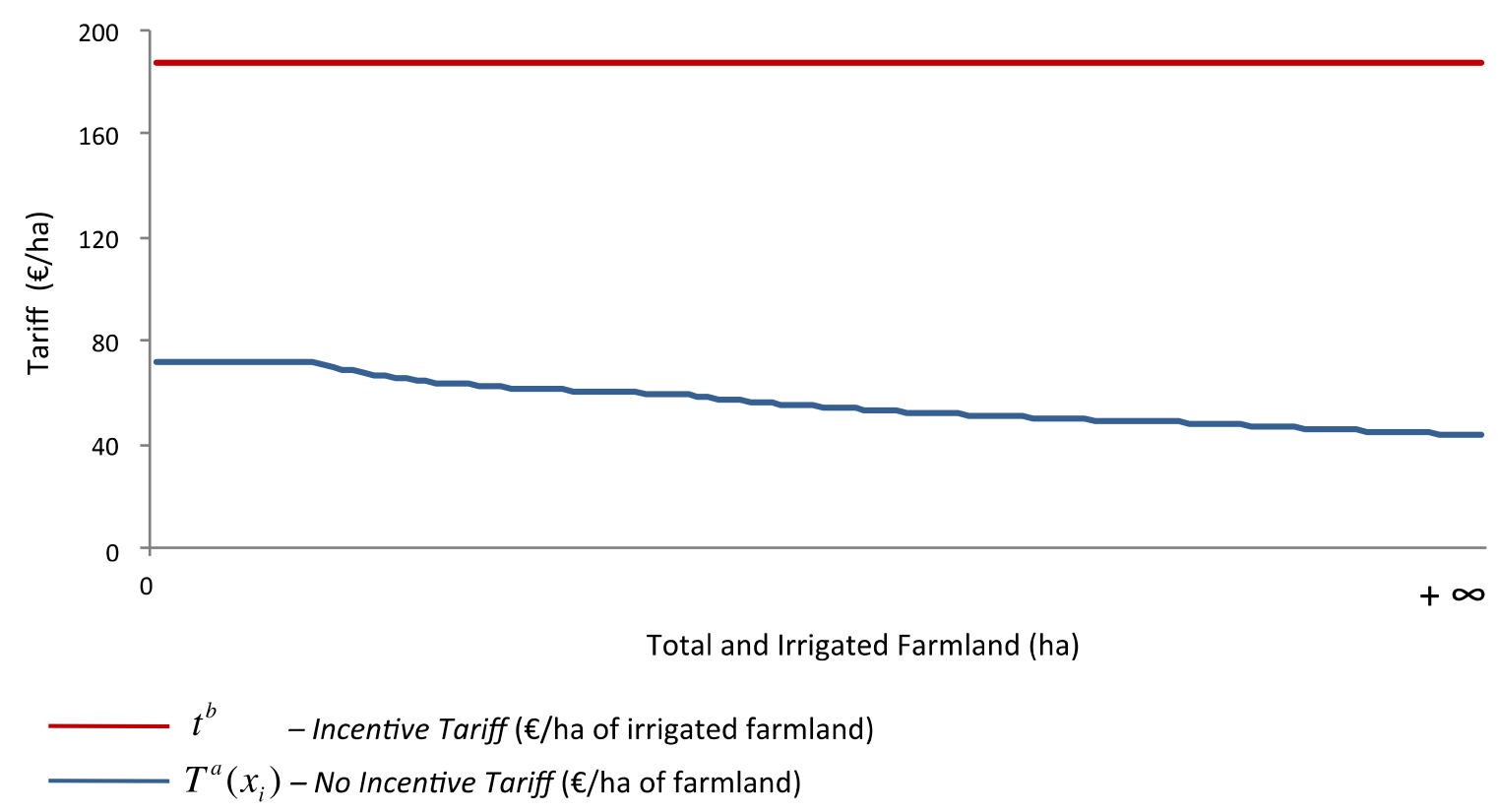

\section{Methodology}

The present section begins first by analyzing how the producers behave given the two tariff alternatives previously described and assuming that the farmer maximizes his/her profits. Then, the methodology shifts from the users to the regulator's perspective. The tariff is no longer exogenously given, as in the producers' problem, but is rather endogenous to the regulator's problem. The key parameter driving the decision is the cost of water. Once the public problem is defined we consider two scenarios. The first scenario reflects the present situation. Here, the water use cost is assumed to be perceived directly by the regulator but the tariff instrument is used only to recover operational costs. The second scenario assumes the commitment to FCR and perfect information by the regulator regarding farmer types (technology). It reflects the theoretical situation in which the water use cost is entirely transferred to the producers by the tariff instrument, while maintaining the current tariff structure.

In the producer problem, given the RIB's pricing options, and assuming that the farmer maximizes his/her profit and that the share of irrigated area has already been established, the choice of the tariff option by the farmer, $T_{i}^{k^{*}}$, may be expected to be directed towards the less costly option:

$$
T_{i}^{k^{*}}=\min \left[T^{a}\left(x_{i}\right), T^{b}\left(x_{i}^{i r r}\right)\right] \quad \forall i, \text { with } k=\{a, b\}
$$

where $a$ and $b$ reflect the two tariff options and $k^{*}$ is the one chosen. If $T^{a}\left(x_{i}\right) \leq t^{b} \times x_{i}^{i r r}$, then $T^{a}\left(x_{i}\right)$ will be preferred over $T^{b}\left(x_{i}^{i r r}\right)$. That is, as long as $x_{i}^{i r r} \geq T^{a}\left(x_{i}\right) / t^{b}$ the farmer is induced to opt for the no incentive tariff. Otherwise, the farmer is induced to opt for the incentive tariff.

Thus, the ratio between the average value of the no incentive tariff and the marginal value of the incentive tariff, which decreases as farmland increases, provides a threshold, $\operatorname{Tr}_{i}$, such that $\operatorname{Tr}_{i}=T^{a}\left(x_{i}\right) / t^{b}=x_{i}^{i r r}$. This threshold, on the basis of the actual quota of irrigated farmland, marks the transition from preferring one tariff to preferring the other. 
The previous model can be reformulated by removing the hypothesis that the share of irrigated area has already been established by the farmer, thus conditioning the choice of the tariff to the choice of the optimal share of irrigated farmland. The problem can, therefore, be modeled as a choice between the two pricing options, jointly considering the optimal irrigated area, according to the criterion of profit maximization. Assuming that the per hectare profit function, $\pi_{i}(\cdot)$, is concave and increases as the quota of irrigated farmland increases, with $\pi_{i}^{\prime}\left(x_{i}^{i r r}\right)>0 e \pi_{i}^{\prime \prime}\left(x_{i}^{i r r}\right) \leq 0$, the farmer compares the profit that can be obtained under each tariff option:

$$
\Pi_{i}^{k}\left(x_{i}^{i r r^{*}}\right)=\max \left[\pi_{i}\left(x_{i}^{i r r^{*}}\right)-T^{a}\left(x_{i}\right), \quad \pi_{i}\left(x_{i}^{i r r^{*}}\right)-T^{b}\left(x_{i}^{i r r_{b}^{*}}\right)\right]
$$

$\Pi_{i}^{k}\left(x_{i}^{i r r^{*}}\right)$ is the maximum profit that can be obtained as a result of both the choice of tariff type and share of irrigated area; $x_{i}^{i r r^{*}}, x_{i}^{i r r_{b}^{*}}$ are respectively the optimal quota of irrigated areas in each tariff option (resulting from the relevant first derivative of the difference between profits and the optional tariffs); accordingly, $x_{i}^{i r r *}$ is the optimal share of irrigated farmland resulting from the higher value of the net profit options.

The tariff choice, $T_{i}^{k^{*}}$, does not necessarily match the minimum value of the two tariff options as given in Equation (1). Here, when the first option of Equation (2) is greater than the second, $\pi_{i}\left(x_{i}^{i r *_{a}}\right)-T^{a}\left(x_{i}\right) \geq \pi_{i}\left(x_{i}^{i r r *_{b}}\right)-t^{b} \times x_{i}^{i r r *_{b}}$, then the farmer will opt for the no incentive tariff, $T_{i}^{k^{*}}=T^{a}\left(x_{i}\right)$. That is, as long as $x_{i}^{i r r_{b}^{*}} \geq T^{a}\left(x_{i}\right) / t^{b}-\left[\pi_{i}\left(x_{i}^{i r r^{*}}\right)-\pi_{i}\left(x_{i}^{i r r_{b}}\right)\right] / t^{b}$ the farmer is induced to opt for the no incentive tariff. Otherwise, the farmer is induced to opt for the incentive tariff.

The tariff option threshold, $T r_{i}$, is no longer compared with a given share of irrigated farmland, but rather with the optimal share of irrigated farmland resulting from the choice of the incentive tariffs, $x_{i}^{i r *_{b}}$, plus the ratio between the differences in gross profits and the incentive tariff, $\left[\pi_{i}\left(x_{i}^{i r r_{a}^{*}}\right)-\pi_{i}\left(x_{i}^{i r r_{b}^{*}}\right)\right] / t^{b}$, and such that: $\operatorname{Tr}_{i}=T^{a}\left(x_{i}\right) / t^{b}=x_{i}^{i r r}+\left[\pi_{i}\left(x_{i}^{i r r^{*}{ }_{a}}\right)-\pi_{i}\left(x_{i}^{i r r_{b}}\right)\right] / t^{b}$. The value of this last argument is always positive as $x_{i}^{i r r_{b}{ }_{b}} \leq x_{i}^{i r r_{a}^{*}}$ [25]. As a result, the threshold tends to be higher than the ones obtained in Equation (1). This is consistent with the fact that this second modeling option allows for more flexibility in farm adaptation, which is, by the way, closer to reality.

In brief, the choice threshold is conditioned both by the public pricing policies and the intrinsic characteristics of each farm type. Both the relative values of the price schemes $\left(T^{a}\left(x_{i}\right) / t^{b}\right)$ and the absolute values of the incentive tariff $\left(t^{b}\right)$ play a key role in conditioning private choices with different results, depending on how farm types differ.

Assuming that the regulator is acting in compliance with the FCR principle, the cost of water use ( $v$, in $€ / \mathrm{m}^{3}$ ) does not depend solely on the current operating costs, but is rather tied to other costs, including environmental and opportunity costs. These costs should be charged to the recipients on the basis of the respective degree of responsibility. Environmental externalities are related to pollution and to an excessive use of water. In the present study it is assumed that the unit cost of water usage, $v$, is proportional to irrigation water use and that the amount of water use per hectare of irrigated land varies across farms. Hence, the total per hectare water use cost is directly connected to water uses, $W_{i}\left(x_{i}^{i r *^{*}}\right)$, that differ as both farm types, $i$, and irrigated farmland, $x_{i}^{i r * *}$, differ, and such that: $C W_{i}\left(x_{i}^{i r r *}\right)=V \times W_{i}\left(x_{i}^{i r r *}\right)$.

The public regulator is assumed to act in the interests of the community by regulating the choices of individuals in order to seek an optimal use of the resources. Formalizing the problem we have: 


$$
\begin{gathered}
\max Z\left(x_{i}^{i r r^{*}}\right)=\gamma_{i} \times\left[\sum_{i=1}^{n} \pi_{i}\left(x_{i}^{i r r^{*}}\right)-C W_{i}\left(x_{i}^{i r r^{*}}\right)\right] \\
\text { FCR } T_{i}^{k^{*}} \geq C W_{i}\left(x_{i}^{i m r^{*}}\right) \\
\text { where } x_{i}^{i r r^{*}}=f\left(T_{i}^{k}\right), \quad x_{i}^{i r r^{*}} \geq 0
\end{gathered}
$$

$Z\left(x^{\text {irr* }}\right)$ is the objective variable and represents the per hectare net social benefit, of a regulator that acts in the interests of the society as a whole; this is an often used assumption in environmental-economic modeling. This is given by summing the weighted differences between the per hectare profits (excluding water tariffs) of each type of user under the regulator's jurisdiction (here, farmers) and the corresponding costs associated to water uses, considered to be borne by society. The weighting term, $\gamma_{i}$, is the share of each farm type, given by the ratio between the total agricultural area related to each farm type and the overall agricultural area under the regulator's jurisdiction. Farmers do not directly perceive water use costs as water is managed collectively and costs are transferred to users via tariffs. Thus, tariffs are not costs per se, but rather constitute transfers and do not enter into the objective function of the regulator (while they remain costs from the farmers' point of view).

FCR is the constraint of full cost recovery for water use. According to the full cost recovery principles, it requires tariffs that are able to recover the cost of water uses and according to the polluter pays principle it imposes tariffs that are at least equal to the water use costs borne by each type of farm. Note that this interpretation is stricter than the one actually given in the implementation of the WFD, which applies to entire sectors and not to individual users.

$x_{i}^{i r r^{*}}=f\left(T_{i}^{k^{\prime}}\right)$ derives from the private problem and is the reaction function of the irrigated farmland for each farm type that varies as the RIB's pricing policy changes. An additional condition is $x_{i}^{i r r^{*}} \geq 0$.

The cost function associated with the use of irrigation water $\left[C W_{i}\left(x_{i}^{i r r^{*}}\right)\right]$ is primarily faced by the RIB as a result of users' decisions (farmers). Currently, as previously stated, the RIB ascribes only a part of the cost recovery to the recipients. The FCR constraint is activated if the regulator acts in compliance with the WFD. Hence, costs are directly shifted to producers by way of the tariff. Under such circumstances, the awareness of farm types allows the RIB to identify the optimal mix of tariff levels that minimize the impact of water use costs on farm profits. If the regulator does not comply with the WFD, the effort to optimize tariff strategies is not justified as most of the social cost of water uses is borne by society and not directly by farmers.

We test the model above using two scenarios and for increasing values of water use costs, which is expected to be one of the major drivers of the actual social desirability of more complex pricing solutions. The current water use costs corresponding to the full cost are currently unknown in the area, so a parametrization in a reasonable range was carried out for financial capital, environmental and resource costs to be considered in addition to operational costs.

Specifically, in a first scenario it is assumed that, regardless of the cost of water use, the RIB ignores the requirements imposed by the WFD (FCR constraint) without changing its pricing policies, hence keeping constant the marginal values of the tariff options $\left(\bar{T}_{i}^{k^{*}}\right)$. This is the present situation that considers only the recovery of the operational costs. Additional costs are implicitly left to be borne by society. 
In a second scenario it is assumed that the RIB knows the profits and water use functions of its members. Under these conditions, the regulator is able to predict producers' reactions to a tariff variation and, hence, to act appropriately on tariff variations in order to optimize the collective benefit.

\section{Results}

The methodology was implemented in the case study using a recent estimation of the per hectare profit and water use function of two farm types in the RIB's region [15].

Figure 2 shows the marginal profit functions of the farm types and the marginal functions of the tariff options offered by the RIB. The slope of the profit functions depends on the crops grown by each farm types. Profit functions cross the $x$-axis to a point corresponding with the optimal quota of irrigated farmland under the no incentive tariff regimes, $x_{i}^{i r{ }^{*}{ }_{a}}$ (respectively point A and B in Figure 2). The horizontal line represents the marginal value of the incentive tariff, $t^{b}$. The projection on the $x$-axis of the crossing point between the marginal tariffs and the profit function of the two farm types (respectively points A and D in Figure 2) is the optimal quota of irrigated farmland under the incentive tariff regimes for each type, $x_{i}^{i r r^{*}}$ (respectively points $\mathrm{C}$ and $\mathrm{F}$ in Figure 2).

The dotted vertical lines in Figure 2 show the tariff thresholds obtained in Equation (4) for each farm type. The thresholds cross the $x$-axis to a point the value of which is given by adding to the optimal quota of irrigated farmland under the incentive tariff regimes, $x_{i}^{i r r_{b}{ }_{b}}$, the ratio between the gross profit differences with the two tariff options and the incentive tariff, $\left[\pi_{i}\left(x_{i}^{i r r^{*}{ }^{a}}\right)-\pi_{i}\left(x_{i}^{i r r^{*}}\right)\right] / t^{b}$. The gross profit differences correspond to the triangular areas ABC and DEF in Figure 2 respectively for the two farm types. The height of those areas matches the level of the incentive tariff. Thus the threshold can be rewritten as follows: $\operatorname{Tr}_{i}=x_{i}^{i r r_{b}^{*}}+\left(x_{i}^{i r^{i}{ }^{*}}-x_{i}^{i r r_{b}^{*}}\right) / 2$.

For a tariff ratio equal to the threshold farmers are indifferent to both tariff regimes. Hence, the discriminatory power of the optional tariffs is null. If the relative ratio between the tariffs is higher than the threshold, farmers will opt for the incentive tariff $\left[T^{b}\left(x_{i}^{i r_{b}}\right)\right]$. As a result, the irrigated farmland decreases by a quota corresponding to the difference between the intersection of the marginal profit function with the $x$-axis and the projection of the intersection of the marginal profit function with the incentive tariff level. Currently the tariff ratio, $T^{a}\left(x_{i}\right) / t^{b}$, is lower than the threshold for both farm types. However, few farms, only partially represented by the type associated to their characteristics, currently opt for the incentive tariff. Hence, because of the present tariff option levels most of the farmers agree with the no incentive tariff, $T^{a}\left(x_{i}\right)[26]$.

The private problem helps to understand how the public decision-maker should direct its pricing strategies in light of the new challenges imposed by the WFD.

Figure 3 shows the collective benefit of the two scenarios described in the methodology. In the first scenario, tariff choice conditions are constant and reflect the repayment of the delivery costs borne by the water authority. Producers do not pay any additional costs that are assumed to be charged to society.

In the second scenario it is assumed that the regulator is aware of the users' production and irrigation schemes and the costs associated with the use of irrigation water are entirely transferred to the producers. With respect to the other scenarios, the regulator is induced to minimize the impact on users' benefits by setting the optional tariff. 
Figure 2. Profit and tariff functions with increasing quotas of irrigated farmland.

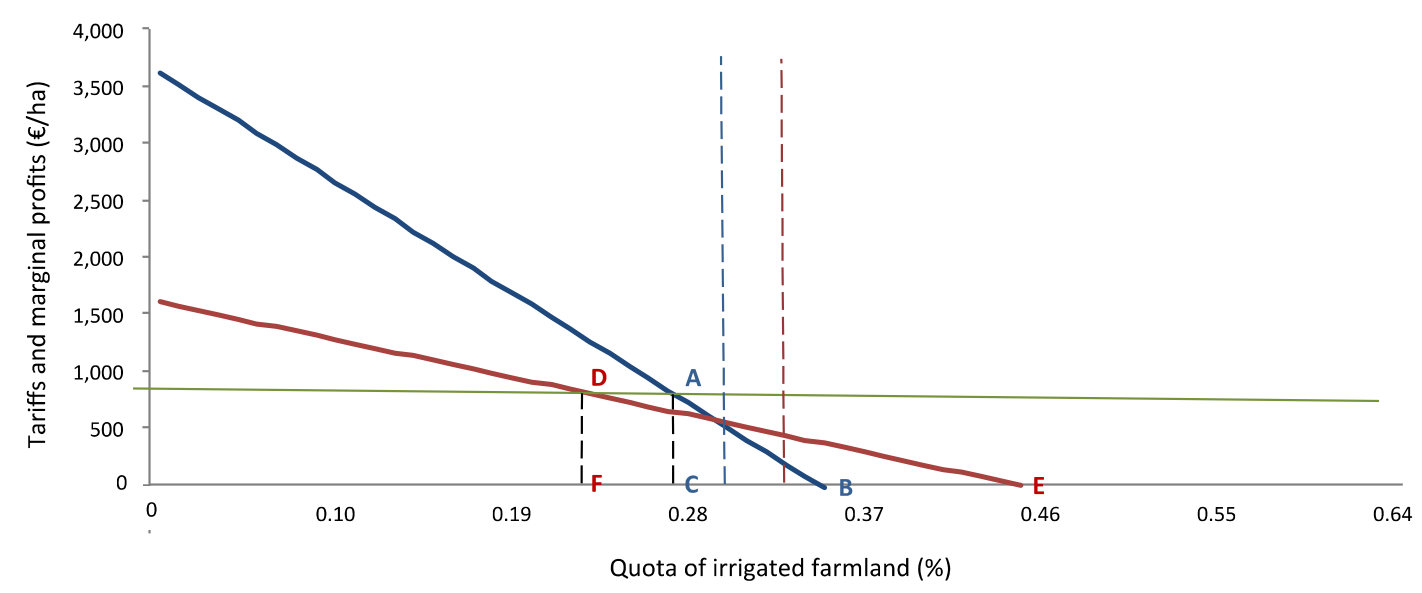

$$
\begin{gathered}
--- \text { Tariffs choice thresholds of the two farm typologies } \\
- \text { Marginal profits of the two farm typologies } \\
\text { Marginal value of the incentive tariff }
\end{gathered}
$$

Figure 3. Benefit trends with increasing irrigation costs for the two scenarios.

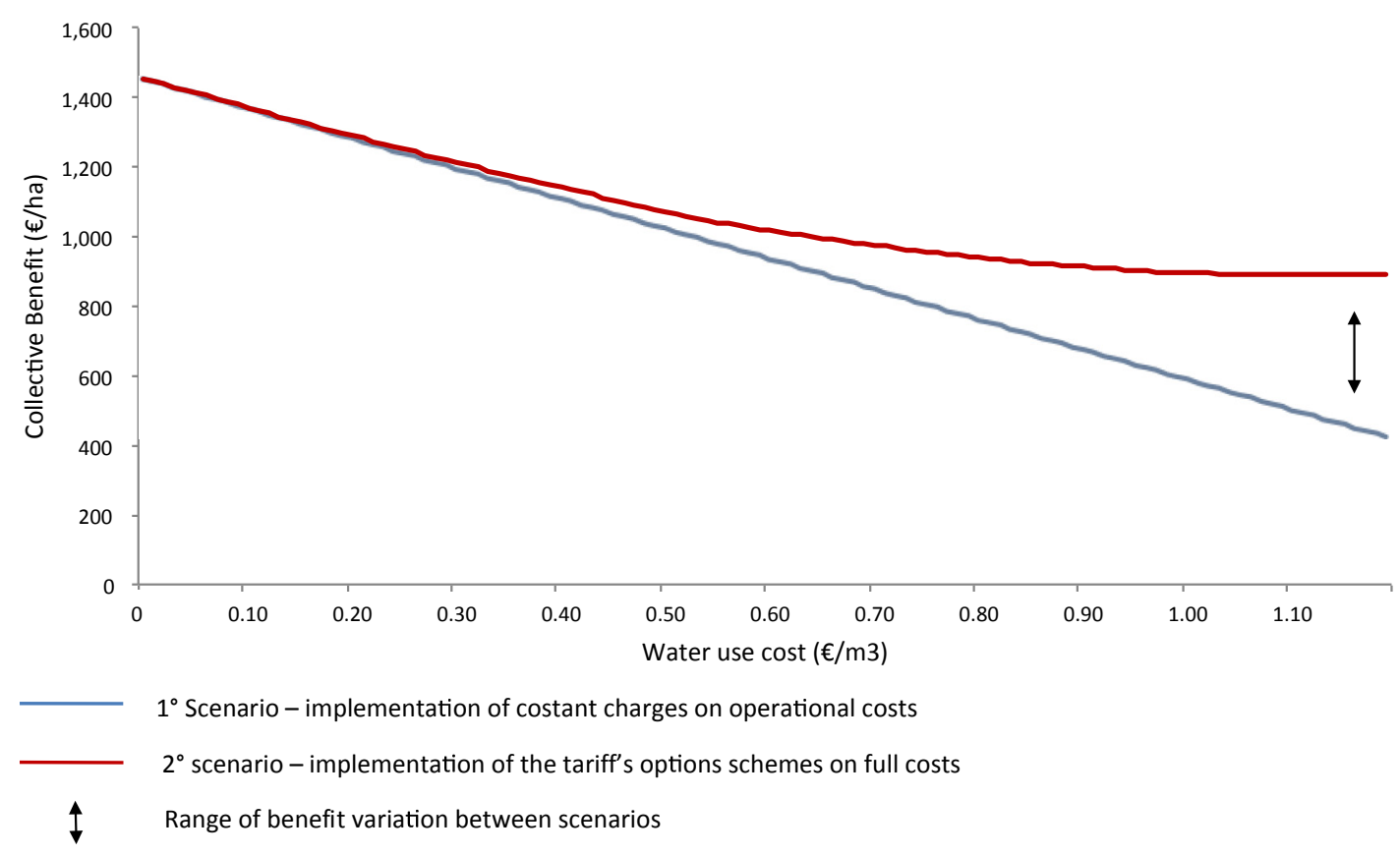

Benefit differences between the two scenarios mark the acceptable limit of the transaction costs that would arise with the adoption of the incentive tariffs in the second scenario. Up to a water use cost of $0.30 € / \mathrm{m}^{3}$ differences in benefits between the two scenarios are not significant: In between $0.30 € / \mathrm{m}^{3}$ and $1.00 € / \mathrm{m}^{3}$ differences in benefit increase from about $0 € /$ ha to $30 € /$ ha. From a water use cost of $1.00 € / \mathrm{m}^{3}$ the trend in benefits in the second scenario remains constant, while in the first scenario it still decreases. This is due to the fact that in the second scenario for increasing levels of water use costs the regulator tends to set tariff options in such a way as to induce an increasing number of farmers to choose the incentive tariff up until a value at which all farm types cease to irrigate. Currently, farmers served by pressure pipes in the region under the case study jurisdiction pay volumetric tariffs equal to $0.12 € / \mathrm{m}^{3}$. The level of the current tariffs is much lower than the value at 
which it is possible to ascertain appreciable differences in benefits between the two scenarios. This fact helps justify why the RIB is limiting the enforcement of tariff options to a few farms.

Figure 4 shows the trend of the quota of irrigated farmland with increasing water use costs for the different scenarios. For the first and second scenarios water use costs do not condition farmers' water uses. In the first scenario, this is due to the absence of a tariff policy that endogenizes any externalities associated with the use of water for irrigation purposes. In the second scenario, a tariff disconnected from water uses is the explanation of farmers' indifference to increasing water use costs.

Figure 4. Quota of irrigated farmland trends with increasing irrigation costs for the two scenarios.

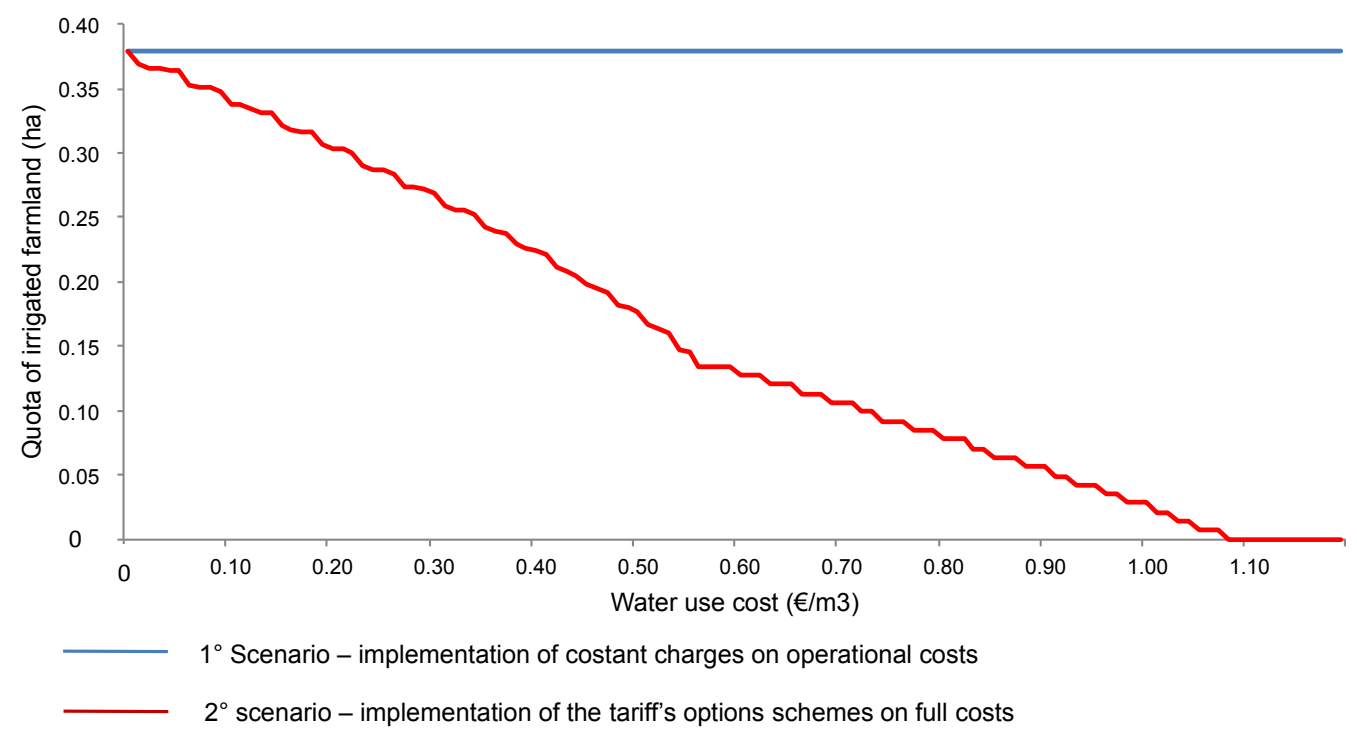

Even if indirectly, only the second scenario shows the existence of a relation between water use costs and water uses. The relation between the water use cost level and the quota of irrigated farmland in the second scenario is explained by the fact that at least one of the two farm types considered in this paper opts for the incentive tariff. The change in slope of the red line in Figure 4 results from a variation in tariff choices. This variation occurs in favor of the incentive tariff as the quota of irrigated farmland continues to decrease with increasing water use costs to a level at which all farms cease to irrigate.

For a cost of water equal to $0.12 \epsilon / \mathrm{m}^{3}$, corresponding to the current value for volumetric tariffs in the case study region, the second scenario shows a 5\% reduction in the irrigated land share. A $400 \%$ increase in the cost of water with respect to the current value bring to a $50 \%$ reduction in the irrigated land share, while an $800 \%$ increase in the cost of water induces farmers to cease irrigation.

\section{Discussion and Conclusions}

The aim of this study was to verify whether the existing tariff strategies for irrigation water are efficient economic instruments for water policy and to what extent alternative designs could help in better managing water demand in the absence of water metering.

Specifically, the paper discusses the design of a pricing strategy presently applied in the case study area that, with the addition of reasonable monitoring costs, allows for the implementation of an incentive tariff which approximates a volumetric pricing scheme by coupling tariffs to the irrigated area. 
According to the scenarios proposed, the implementation of the WFD principles should enable the regulator to recover the full cost needed to provide services. The modification of the existing tariff policies, presently based on an area-based flat rate system, is justified if transaction costs, due to the need to monitor at least irrigated areas under no metering conditions, are lower than the difference in benefit between the two scenarios. From this perspective, the RIB should adjust the tariffs for irrigation water uses according to the type of priority (funding and/or environmental protection) and in compliance with the criterion of cost sharing (equity). As noted in the results, this may, at least partially, resolve the problem of asymmetric information. Indeed, even if farmers' profit and water use functions are unknown, the tariff options, if properly calibrated, would lead some farmers to choose the incentive tariffs, hence revealing their water profitability. This would lead to an intermediate situation between the two extreme scenarios that includes, on the one hand, the absence of any volume-related pricing policy and, on the other, a meticulous tariff plan modulated on the marginal productivity of each farm type.

Although using quite different premises from those in our study, other recent studies have analyzed the implementation of alternative water pricing policies for irrigation [10,11]. Specifically, the analysis of Veettil et al. [10] in the Krishna River basin, India, demonstrated that farms served in the absence of water metering tend to opt for incentive tariff schemes mostly for high levels of water use costs. This is also consistent with our study in which the current low level of cost recovery does not justify the adoption of the alternative tariff by any of the farm types served by the RIB. Moreover, Fragoso and Marques [11], in a study carried out in the Alentejo region of Portugal, identified volumetric block tariffs as the most efficient incentive strategy. This is due to the fact that farmers mostly used to have a demand elasticity for irrigation water that increases with increasing water use cost. In the absence of water metering this would probably result in the identification of fixed charge quotas as being the best incentive strategy. However, beyond comparing the tariff schemes, the main purpose of the present study was to analyze the regulator's behavior under different policy scenarios, given a discriminatory strategy that consists of the implementation of two tariff options. This is very relevant in the case study areas as it allows for the identification of incentives to lower water demand without major changes to the existing pricing structure and without water metering.

Thus, the study describes a discriminatory strategy that enables the regulator to partially control water use in surface water delivery systems serving a large number of farms (specifically the RIBs of Western Romagna). Under such circumstances, incentive strategies are considered prohibitively expensive [2]. That is why the regulator is currently limiting the implementation of the tariff option schemes to only a few farms.

An important limitation of the research is found in the simplified description of the two scenarios. Compliance or not with WFD principles on water pricing is the principal difference between the two scenarios. However, we only analyzed the effects related to the implementation of the incentive pricing principles. The other two principles appear as assumptions of the regulator's maximization problem and are implicit in the FCR constraint. The polluter pays principle is also implicit in the regulator's tariff policies. Moreover, the FCR constraint at the farm level is an exacerbation of current regulatory guidance. Charging full costs to individual farmers is in fact beyond the prescriptions of the WFD, which recommends implementing its principles for the agricultural sector as a whole, and at the river basin district level, but not at the level of each individual water service user [27]. 
Another significant limitation arises from the assumption of perfect information under the scenario in which compliance with the WFD principles is assumed. In the absence of water metering, the regulator would not be able to determine the technology used (farm types) nor control water use (irrigated land). This condition implicitly poses the two main problems of asymmetric information: adverse selection and moral hazard. Smith and Tsur [12] were the first to tackle both problems theoretically, but only adverse selection has actually been tested [15]. The ability to deal with adverse selection allowed Viaggi et al. [15] to distinguish tariffs according to farmers' water use attitudes; hence substantially increasing performances with respect to there being no discrimination. The discriminatory strategy described in this paper in addition to tariff options would probably further improve the discriminatory power of the regulator, strengthen its ability to minimize the impact of water tariffs on farm profits, while providing more adequate incentives.

Currently there are no studies, including this one, which directly tackle the issues of moral hazard. This is the main limiting factor of the present study as moral hazard conditions the extent to which monitoring activities enables the regulator to implement incentive strategies in the absence of water metering. In this study, the differences in performance between the two scenarios limit the monitoring costs due to the need to control irrigated land that would arise with the adoption of the incentive tariff. As a result, by adjusting tariff option levels, the regulator would be able to foresee how many farms will opt for the incentive tariff and hence control both water uses and monitoring costs. Thus, the discrimination strategy described in this paper could be considered as a starting point for the analysis of moral hazard in the absence of water. Specifically, the main question with respect to water pricing in the absence of metering is to recognize the most cost effective monitoring strategies that would enable the regulator to overcome moral hazard arising from false reporting. This last consideration suggests a new direction for further research.

\section{Acknowledgments}

The authors wish to thank the anonymous referees for the fruitful suggestions and David Cuming for English editing. Responsibility for the contents of the study lies solely with the authors.

\section{Conflicts of Interest}

The authors declare no conflict of interest.

\section{References and Notes}

1. Christian, J.S.; Gleick, P.H.; Cooley, H. US Water policy reform. In The World's Water: The Biennial Report on Freshwater Resources; Gleick, P.H., Ed.; Island Press: Washington, DC, USA, 2011.

2. Molle, F.; Berkoff, J. Water pricing in irrigation: Mapping the debate in the light of experience. In Irrigation Water Pricing: The Gap between Theory and Practice; Molle, F., Berkoff, J., Eds.; CAB International: Wallingford, UK, 2007; pp. 21-93.

3. Moore, M.; Gollehon, N.; Carey, M. Multicroop production decisions in western irrigated agriculture: The role of water price. Am. J. Agric. Econ. 1994, 76, 859-874. 
4. Gardner, B.D. Some implications of federal grazing, timber, irrigation, and recreation subsidies. Choices 1997, 12, 9-14.

5. Schaible, G.D. Water conservation policy analysis: An interregional, multi-output, primal-dual optimization approach. Am. J. Agric. Econ. 1997, 79, 163-177.

6. Iglesias, E.; Garrido, A.; Sumpsi, J.; Varela-Ortega, C. Water demand elasticity: implications for water management and water pricing policies. In Proceedings of the World Congress of Environmental and Resource Economists, Venice, Italy, 26-29 June 1998; pp. 1-16.

7. Varela-Ortega, C.; Sumpsi, J.M.; Garrido, A.; Blanco, M.; Iglesias, E. Water pricing policies, public decision making and farmers' response: Implications for water policy. Agric. Econ. 1998, 19, 193-202.

8. Berbel, J.; Gomez-Limon, J.A. The impact of water-pricing policy in Spain: An analysis of three irrigated areas. Agric. Water Manag. 2007, 43, 219-238.

9. Yang, H.; Zhang, X.; Zehnder, A.J.B. Water scarcity, pricing mechanism and institutional reform in northern China irrigated agriculture. Agric. Water Manag. 2003, 61, 143-161.

10. Veettil, C.P.; Speelman, S.; Frija, A.; Buysse, J.; Mondelaers, K.; van Huylenbroeck, G. Price sensitivity of farmer preferences for irrigation water-Pricing method: Evidence from a choice model analysis in Krishna River Basin, India. J. Water Resour. Plan. Manag. 2011, 137, 205-214.

11. Fragoso, R.; Marques, C. The Economic Impact of Alternative Water Pricing Policies in the Alentejan Region; CEFAGE-UE Working Paper; University of Evora: Evora, Portugal, 2013.

12. Smith, R.B.W.; Tsur, Y. Asymmetric information and the pricing of natural resources: Understanding the case of unmetered water. Land Econ. 1997, 73, 392-403.

13. Bogaert, S. The Role of Water Pricing and Water Allocation in Agriculture in Delivering Sustainable Water Use in Europe; European Commission: Brussels, Belgium, 2012.

14. Bazzani, G.M.; di Pasquale, S.; Gallerani, V.; Viaggi, D. Irrigated agriculture in Italy and water regulation under the European Union Water Framework Directive. Water Resour. Res. 2004, 40, $1-8$.

15. Viaggi, D.; Raggi, M.; Bartolini, F.; Gallerani, V. Designing contracts for irrigation water under asymmetric information: Are simple pricing mechanisms enough? Agric. Water Manag. 2010, 97 , 1326-1332.

16. Bowen, R.; Young, R. Allocative impacts on alternative methods of charging for irrigation water in Egypt. In Irrigation Investments, Technology and Management Strategies for Development; Ester, K.W., Ed.; West View Press: Boulder, CO, USA, 1986.

17. Besanko, D.; Sappington, D. Designing Regulatory Policy with Limited Information; Harwood Academic Publisher: Newark, NJ, USA, 1987.

18. Smith, R.B.W. The conservation reserved program as a least-cost land retirement mechanism. Am. J. Agric. Econ. 1995, 77, 93-105.

19. Schlagler, E.; Ostrom, E. Property rights regimes and natural resources: A conceptual analysis. Land Econ. 1992, 68, 249-262.

20. Coletta, A. Pricing strategies for commons: The case of water users association for irrigation. Riv. Econ. Agrar. 2010, 4, 619-635. 
21. Testo unico delle disposizioni di legge sulle acque e impianti elettrici. Avaliable online: http://www.google.com.hk/url?sa=t\&rct=j\&q=\&esrc=s\&source=web\&cd=1\&ved=0CCoQFjAA\& url=http $\% 3 \mathrm{~A} \% 2 \mathrm{~F} \% 2 \mathrm{Fwww}$. sportelloenergia.info $\% 2$ Findex.php $\% 3$ Faction $\% 3$ Ddownload_resourc e\%26id\%3D112\%26module\%3Dresourcesmodule\%26src\%3D\%2540random4a647f4e18d8e\&ei $=$ UMA-UIDEyq0Ble6A4As\&usg=AFQjCNE8hhWniPxcHbTlErxLOZeshmpmWw (accessed on 12 March 2013).

22. Carlton, D.W.; Perloff, J.M. Modern Industrial Organization, 3rd ed.; Pearson-Addison Wesley: New York, NY, USA, 2005; pp. 32-55.

23. Gallerani, V.; la Via, G.; Zanni, G. Water and Agriculture in Italy: Decision Rules and Scenario Analysis, 1st ed.; Franco Angeli: Milano, Italy, 2009; pp. 62-84.

24. The Basin District consists in one or more watersheds (territorial unit where all surface water flow into the sea in a single estuary (article 2 [27] paragraph 13, WFD) defined as the main territorial unit for river basin management (article 2 [27] paragraph 15, WFD).

25. Indeed, by deriving the differences between the gross profit function and the relative tariffs with respect to the irrigated area for each farm type the optimal solution is reached at the equality between marginal profits and marginal tariffs:

$$
\begin{aligned}
& \partial \Pi_{i}^{k} / \partial x_{i}^{i r r}=\pi_{i}^{\prime}\left(x_{i}^{i r r}\right)-T_{i}^{k^{\prime}}\left(x_{i}^{i r r}\right)=0 \\
& \text { if } \quad k=a, \pi_{i}^{\prime}\left(x_{i}^{i r r}\right)=0 ; \quad \text { if } \quad k=b, \pi_{i}^{\prime}\left(x_{i}^{i r r}\right)=T^{b}
\end{aligned}
$$

The value of $k(a, b)$ reflects the tariff choice subject to the optimal share of irrigated area $\left(x_{i}^{i r *^{*}}\right)$. The first tariff scheme $\left[T^{a}\left(x_{i}\right)\right]$, being disconnected from the irrigated farmland, does not affect water consumption $\left[\partial T^{a}\left(x_{i}\right) / \partial x_{i}^{i r r}=0\right]$. In contrast, assuming a positive correlation between water consumption and irrigated areas, $T^{b}\left(x_{i}^{i r r}\right)$ is able to influence water uses $\left(\partial T^{b}\left(x_{i}^{i r r}\right) / \partial x_{i}^{i r r}=T^{b}\right)$. Consequently, given the technology, producers subject to the first tariff scheme will maximize profits at higher shares of irrigated areas than would farmers who choose the other tariff. Then, from the first order condition of the above problem we achieve the farmland share at which producers direct their own choices, which in turn is a function of the marginal tariffs $\left[x_{i}^{i r *^{*}}=f\left(T_{i}^{k^{\prime}}\right)\right.$ with $\left.f^{\prime}\left(T_{i}^{k^{\prime}}\right)<0\right]$.

26. In fact, the optional scheme in force in the case study area induces few farmers to choose the incentive tariff. Their numbers proved to be too inconsistent for the identification of the five main farm types populating the RIB's area. As a result, the optional tariff seems to have no discriminatory power.

27. European Union. Directive $2000 / 60 / \mathrm{EC}$ of the European parliament and of the council establishing a framework for community action in the field of water policy. Off. J. Eur. Communit. 2000, 327, 1-72.

(C) 2013 by the authors; licensee MDPI, Basel, Switzerland. This article is an open access article distributed under the terms and conditions of the Creative Commons Attribution license (http://creativecommons.org/licenses/by/3.0/). 